\title{
Corporate Philanthropy and Innovation Performance
}

\author{
Shaoyan Jiang ${ }^{1}$, Jingwen $\mathrm{Mi}^{1}$, Xiaohui $\mathrm{Tao}^{1} \&$ Wanwan $\mathrm{Hu}^{1}$ \\ ${ }^{1}$ International Business Institute, Jinan University, Zhuhai, China \\ Correspondence: Jingwen Mi, International Business Institute, Jinan University, Zhuhai, China. E-mail: \\ 609735188@qq.com
}

Received: February 6, 2018

Accepted: February 26, 2018

Online Published: March 18, 2018

doi:10.5539/ijbm.v13n4p173

URL: https://doi.org/10.5539/ijbm.v13n4p173

\begin{abstract}
Corporate Philanthropy and innovation performance are the focuses of enterprise research in recent years. Based on resource dependence theory and information disclosure theory, the paper explores the impact of philanthropic donations on innovation performance. Through the quantitative data analysis of 319 enterprises in China, the results show that: (1) There is an obviously positive correlation between philanthropic donations and innovation performance, which will be affected by the scale of enterprises. (2) The disclosure of philanthropic information will weaken the promotion effect of philanthropic donation on innovation performance. The conclusion of the study made a useful extension of the existing philanthropic donation literature and provided a theoretical basis for the philanthropic practice of the enterprise.
\end{abstract}

Keywords: Innovation performance, corporate philanthropy, enterprise size, information disclosure

\section{Introduction}

In recent years, the charity donation activities of Chinese enterprises are increasing. Charity donations have drawn wide public concern. As a rational market-oriented enterprise that pursues the maximization of shareholders' value, how can the promotion of philanthropic donations contribute to its profit growth? This is the focus of many scholars in recent years, such as: political motivation(Du Yong \& Chen Jianying, 2016; Dai Yiyi et al, 2014); Marketing motivation (Liu Ying, 2015; Hu Jun, 2017; Park et al, 2016); Management self-motivation (Wang Ying et al., 2017; Chen et al., 2016); Covering the motivation of the lack of corporate social responsibility (Gao Yongqiang et al., 2012; Ni Yinzhu and He Chen, 2016).

Nowadays, many scholars also study the consequences of corporate philanthropic donations from the perspective of corporate financial performance. Lu Zhengwen \& Liu Chunlin (2017), from the perspective of stakeholders, think that the relationship between corporate donation behavior and financial performance is uncertain, which is affected by the intensity of market competition and the fulfillment of basic social responsibilities by enterprises; Gu Leilei and Ouyang Wenjing (2017) think that the contribution of corporate donations to enterprise performance is affected by the marketing capabilities and marketability degree of enterprises. About the influence of philanthropic donation on the enterprise value, the research about the impact of philanthropic donations on the financial performance of enterprises has been very comprehensive, but there are few scholars involved in the impact of philanthropic donations on the innovation performance of enterprises. The improvement of enterprise innovation performance is the manifestation of the enhancement of the scientific and technological strength of enterprises(Wu Chengcheng,2015). In a complex and ever-changing economic environment, enterprises can gain greater space for development only through technological innovation. Under the trend of open innovation and collaborative innovation, enterprise innovation is more and more inseparable from the close cooperation with universities, research institutes, customers( Wang Baolin \& Zhang Mingshen,2015). Therefore, in addition to being responsible for internal stakeholders, the enterprise also needs to be responsible for external interest relevant people and establish good relations with them.

Innovative resources refer to the various inputs required for technological innovation in enterprises and are the foundation and key to enterprise innovation( Zhang Yinghua \& Peng Jianqiang,2016). However, all kinds of technological innovation resources are limited, and enterprises can't obtain the optimal innovation performance only by investing their own resources. And due to the high cost of acquiring innovative resources and the poor management of the enterprise, there is no way for resources to be fully used by the enterprises (Wang Xueyuan et al., 2013). Therefore, it is very important to acquire external resources to complement each other. Chen Shou et 
al. (2015) argue that the synergy of different types of complementary resources and innovation resources has a significant impact on enterprise performance. Through philanthropic donations, it is conducive to establishing good contacts with external resource holders, so as to obtain complementary resources and promote the innovation performance of enterprises. Innovative resources such as from universities and research institutes are important sources of external scientific and technological resources for enterprises. How can enterprises establish good cooperative relations with them? Undoubtedly, philanthropic donations are the inevitable choice for enterprises to establish good cooperative relations with universities and research institutions. In order to further understand the role of philanthropic donations in the innovation and development of enterprises, this paper, from the perspective of corporate technological resources acquisition ability and charity information disclosure, explores the impact mechanism of corporate philanthropic donations on innovation performance through the quantitative data of 315 enterprises. Based on the theories of resource dependence and information disclosure, this paper constructs an moderate effect model of philanthropic donations, enterprise size, informational disclosure and innovation performance, so as to try to answer whether philanthropic donation contributes to innovation or not, which provides a theoretical basis for philanthropic donation practice.

\section{Literature Review and Research Hypotheses}

\subsection{Philanthropic Donations and Innovation Performance}

Existing research shows that philanthropic donations and enterprise performance are closely related, but their results are different, such as, positive relative (Gao Yongqiang, 2010), nothing relative (Zhu Jinfeng \& Zhao Hongjian, 2010), inverted U-shaped relative (Jiang Ruochen et al, 2016). Thus, the relationship between corporate philanthropic donations and enterprise performance is complicated and affected by all aspects. And innovation performance is an important part of enterprise performance. How can philanthropic donation promote innovation performance?

According to the theory of resource dependence, the enterprises themselves can't generate all the resources they need for their development. The survival and development of enterprises depend on the holders of external resources, including universities and research institutes. Sun Hongchang (2006) thinks that if enterprises rely on internal research and development resources alone, they will spend a lot of time on innovation, and then can't reach the optimal innovation. The results of previous studies show that the cooperation between enterprises and universities and research institutes is conducive to business innovation. Frederick et al. (2014) think that enterprises can form an innovative network mechanism with universities, research institutes and other institutions through direct donation, which will help enterprises to obtain external resources, to achieve fast and flexible innovation. Chesbrough (2003) believes that by working with external agencies, companies can gain expertise in different fields and broaden their knowledge base to further their business innovation. Universities and research institutes are important sources of resources for science and technology innovation outside enterprises. Enterprises often establish and maintain friendly relations with universities and research institutes through philanthropy, which will benefit enterprises to obtain external scientific and technological innovation resources. As a result, enterprises can improve their innovation performance, and achieve a win-win situation (Xu Tao \& Wang Ling, 2012).

Based on this, the following assumptions are proposed:

H1: Corporate philanthropic donations have a positive role in promoting innovation performance.

\subsection{The Role of Enterprise Size as an Intermediary between Philanthropic Giving and Innovation Performance}

The scale of an enterprise indicates the degree of concentration of labor, means of production and products in an enterprise. In general, a large enterprise owns sufficient funds and a sound management system, so schools and research institutes tend to choose enterprises with strong economic power and large scale as partners (Liu Wei et al., 2013) to ensure that enterprises can provide sufficient and continuous financial support. There is a close relationship between enterprise size and innovation performance, but there are different opinions on the effect of enterprise size on innovation performance. For example, Huang Jingjing (2017) argues that enterprise size has a positive impact on innovation performance; Chen Kun et al (2016) that there is an inverted U-shaped relationship between enterprise size and innovation performance. The existing literature mainly studies the direct impact of enterprise size on innovation performance. Few literature studies the impact of philanthropic donation on innovation performance based on enterprise size as moderator.

Philanthropic donations are social activities that donate or fund charity organization, including the donation of cash and in kind. Scholars opposed to corporate philanthropy believe that philanthropic donations take up part of the resources of a business and are detrimental to business development (Milton Friedman, 1970). However, 
Jiang Ruochen et al. (2016) argue that philanthropic donations are conducive to promoting financial performance in effective intervals. Enterprises can't give up philanthropic donations for the reason that they may occupy resources for philanthropic donations. Besides, larger enterprises have more funds and equipment, and enterprises are less likely to take up resources of other business activities through philanthropic donations. As a result, the larger enterprises size, the more obvious the contribution of corporate donation to innovation performance.

Based on this, the following assumptions are proposed:

$\mathrm{H} 2$ : Enterprises size will strengthen the role of philanthropic donations in promoting innovation performance.

\subsection{The Role of Disclosure of Philanthropic Information between philanthropic giving and Innovation Performance}

The level of disclosure of philanthropic information means that enterprises disclose their donation information to the public, including the objects and amounts of donation. Whether corporate philanthropic donations should be mandatorily disclosed is still a big controversy in China. Proponents of the charity disclosure system believe that the disclosure of charity information is conducive to safeguarding the interests of enterprise stakeholders, standardizing the self-interest behaviors that business operators may have in philanthropic giving and promoting the development of charities (Li Yuping et al., 2009). But opponents argue that mandatory disclosure risks exposing enterprises to the risks of revealing trade secrets and adversely affecting their business operations (Balotti, 1998). Corporate philanthropy has become a strategic business activity and the disclosure of certain philanthropic donations means that enterprises face the risk that corporate growth strategies are known to competitors (Acharya \& Subramanian, 2009).

In the market competition, especially in the highly competitive industries, enterprises establish good relationships with universities, research institutes, etc. by philanthropic donations, build an innovation network mechanism and promote enterprise innovation. If the charity information is known by competitors and then the competitors may understand the development strategy of enterprises by analyzing philanthropic information, which is not conducive to the further development of enterprises and the improvement of business innovation performance. Therefore, the disclosure of philanthropic information has both advantages and disadvantages. Yang Shuying (2013) and Zhang An-yi (2011) demonstrate that it is necessary that government established an information disclosure system for corporate charity donations from the perspectives of shareholders' interests, bondholders' interests and social public interests, but they also propose that government should take a certain degree of exemption to protect business secrets and promote business innovation. Therefore, the disclosure of charity information is not conducive to the impact of philanthropic donations on the innovation performance of enterprises.

Based on this, this paper proposes the following assumptions:

H3: The level of disclosure of philanthropic information diminishes the role of philanthropic donation in promoting innovation performance.

The theoretical model of this paper is shown in Figure 1.

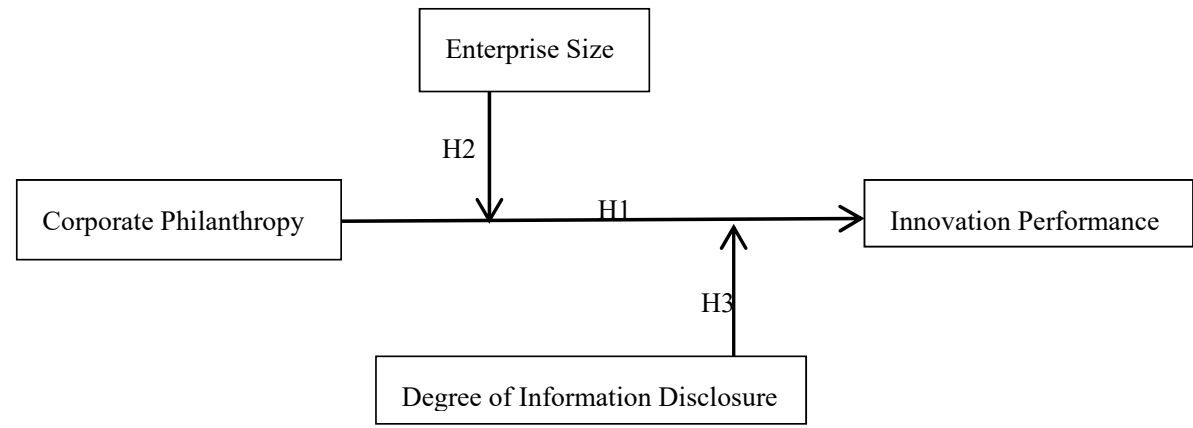

Figure 1. The theoretical model of this paper

\section{Research Design}

\subsection{Sample Selection}

The research object is a listed company that has disclosed the amount of corporate philanthropic donations. The data analyzed mainly comes from the CSMAR database. The statistical time range is from 2011 to 2015 . After eliminating the missing and incompatible samples of important information, the number of the remaining 
enterprises is 319 and the number of samples is 808. In terms of industry distribution, manufacturing industry 241 accounts for $75.55 \%$ of the total; mining industry 19 accounts for $5.96 \%$; construction industry 16 accounts for $5.02 \%$; financial industry 10 accounts for $3.13 \%$; and others 33 account for $10.34 \%$.

\subsection{Variable Measurement}

(1) Innovation Performance (Innov). Chen Qinyuan et al. (2017) found that the increase of the output of patents reflects the improvement of innovation performance of an enterprise. Therefore, this paper uses the output of patents (the number of patent applications) to measure the innovation performance of an enterprise. Patent output includes patent for invention, patent for new use, patent for design. Referring to Li Shi et al (2012) on the three kinds of patent output's influence on enterprise value and taking into account the different impact of these three outputs on innovation performance, this paper respectively gives the weight of $0.5,0.3,0.2$ and then uses weighted summation to measure the innovative performance of enterprises.

(2) Corporate Philanthropy ( Phil). According to Wang \& Qian (2011) and other measurement methods of philanthropic donations, this paper directly use the total amount of actual annual donations of enterprises to measures the amount of philanthropic donations. Considering the time lag of corporate philanthropy on innovation performance, this paper uses the amount of donations made in the year prior to patent output.

(3) Enterprise Size ( Size). Studies have shown that the variables that measure enterprise size are usually total assets, sales revenue and number of employees. Because sales revenue and the number of employees vulnerable to market demand, the economic cycle and other contingent factors, the paper chooses the logarithm of total assets as a measure of enterprise size indicator.

(4) Degree of Information Disclosure (Disclo). In this paper, whether corporate philanthropy is verified by a third party, whether to disclose the construction of social responsibility system and improvement measures, whether disclosure of public relations and public welfare undertakings, etc., are conducted in the form of $0,1(0$ for no and 1 for yes). Then they are summed to indicate the level of corporate philanthropic disclosure.

(5) Control Variables. Reference to the practice of previous literature, the control variables added in the regression model in Table 1.

Table 1. Control variables

\begin{tabular}{lll}
\hline Variable Name & Symbol & Measurement Method \\
\hline Profitability & Profit & $\begin{array}{l}\text { Return on assets of the year prior to patent output } \\
\text { Patent revenue growth in the previous year's } \\
\text { operating income } \\
\text { Growth }\end{array}$ \\
Gro & Year of patent output \\
Year & Year & SFC Classification (17) \\
\hline
\end{tabular}

\section{Outcome of Practice}

\subsection{Descriptive Statistics and Correlation Analysis}

The correlation coefficient, mean and standard deviation of each variable are shown in Table 2. It can be seen that there is a significant positive correlation between philanthropic donations, enterprise size and enterprise innovation performance. There is also a significant positive correlation between enterprise size and philanthropic donations. On the other hand, the correlation coefficient between the variables is less than 0.7 , indicating that the phenomenon of multiple linear problems is not prominent. 
Table 2. Descriptive statistics of variables

\begin{tabular}{lcccccc}
\hline & Innov & Phil & Disclo & Size & Profit & Gro \\
\cline { 2 - 7 } Innov & 1 & & & & & \\
Phil & $0.116^{* *}$ & 1 & & & & \\
Disclo & -0.011 & 0.016 & 1 & & & \\
Size & $0.238^{* *}$ & $0.253^{* *}$ & -0.045 & 1 & & \\
Profit & -0.013 & 0.009 & -0.068 & $-0.261^{* *}$ & 1 & \\
Gro & -0.10 & -0.005 & -0.048 & -0.013 & 0.055 & 1 \\
mean & 52.830 & 1637.589 & 7.951 & 23.421 & 0.064 & 0.242 \\
standard deviation & 200.993 & 7491.233 & 1.314 & 2.132 & 0.060 & 1.571 \\
N & 808 & 808 & 808 & 808 & 808 & 808 \\
\hline
\end{tabular}

Note. ${ }^{* *}$ : Significantly correlated at 0.01 level (bilateral).

\subsection{Multiple Regression Analysis and Hypothesis Testing}

(1) The test of relationship between philanthropic donations and innovation performance

In order to explore the relationship between philanthropic donations and innovation performance, this paper analyzes the impact of philanthropic donations on innovation performance with innovation performance as dependent variable and philanthropic donations as independent variables. The results are shown in Table 3.

Table 3. Philanthropic donations, innovation performance regression analysis of the results

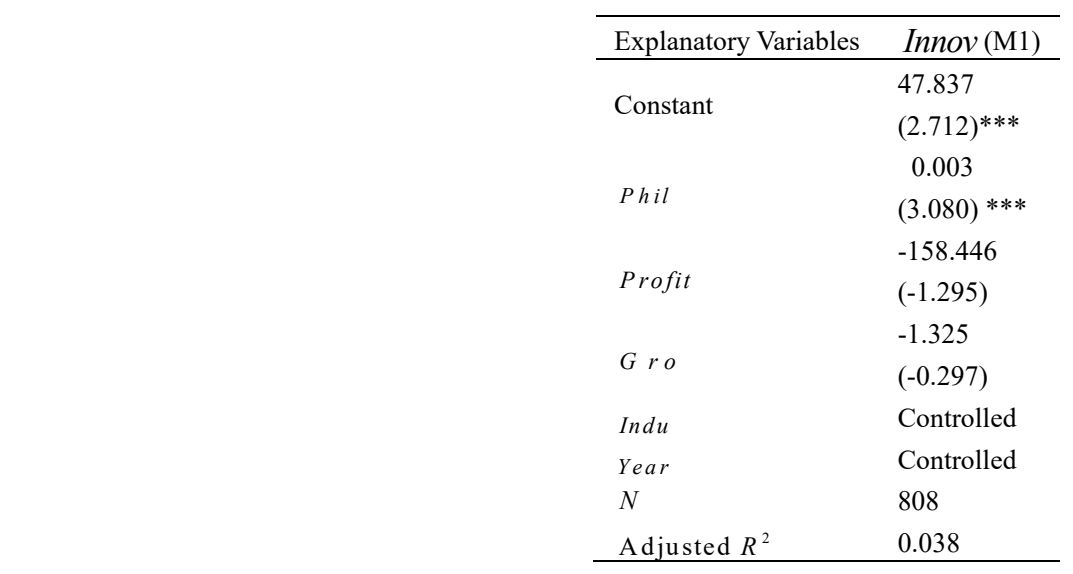

Note. ${ }^{* *}: \mathrm{p}<0.010 ; * *: \mathrm{p}<0.050 ; *: \mathrm{p}<0.100$, the same below.

According to the result of M1 in Table 3, the philanthropic donation's t value is 3.080, so the level of philanthropic donation has a significant role in promoting innovation performance. That is, the higher the level of philanthropic donation, the stronger the promotion effect on innovation performance. Suppose H1 gets support.

(2) Enterprise size and philanthropic information disclosure as moderating variables

In order to verify the role of the two moderating variables between philanthropic and innovation performance, this paper, based on the assumption $\mathrm{H} 1$, first joins two variables of enterprise size and corporate philanthropic information disclosure, and then joins philanthropic donations multiplying with two moderating variables enterprise size and the degree of disclosure, to make multiple regression. The results are shown in Table 4. 
Table 4. Enterprise Size, Degree of Information Disclosure and Results of Regression Analysis of Philanthropic Donations and Innovation Performance

\begin{tabular}{lll}
\hline Explanatory Variables & Innov (M2) & Innov (M3) \\
\hline \multirow{2}{*}{ Constant) } & -1117.220 & -1144.160 \\
& $(-9.648)^{* * *}$ & $(-8.170)^{* * *}$ \\
Phil & 0.002 & 0.002 \\
& $(2.415)^{* *}$ & $(2.153)^{* *}$ \\
Size & 51.386 & 39.509 \\
& $(11.054)^{* * *}$ & $(5.291)^{* * *}$ \\
Disclo & -1.036 & 37.096 \\
& $(-0.205)$ & $(2.977)^{* * *}$ \\
Phil ${ }^{*}$ Size & & 2.607 \\
& & $(3.145)^{* * *}$ \\
Phil ${ }^{*}$ Disclo & & -7.876 \\
& & $(-3.339) * * *$ \\
Profit & 15.224 & 55.813 \\
& $(0.132)$ & $(0.459)$ \\
Gro & -1.819 & -1.403 \\
& $(-0.438)$ & $(-0.339)$ \\
Indu & Controlled & Controlled \\
Year & Controlled & Controlled \\
$N$ & 808 & 808 \\
Adjusted $R^{2}$ & 0.165 & 0.174 \\
\hline
\end{tabular}

According to the analysis results in Table 3, it can be seen that in the M3 model in Table 3, the $t$ values of the interaction items between philanthropic donations and enterprise size are respectively 3.145 . Thus, it can be seen that the size of the enterprises plays a reinforcing role in the impact of philanthropic donations on innovation performance. That is, the bigger the business, the more obvious the impact of philanthropic donations on business innovation performance. Suppose $\mathrm{H} 2$ gets support.

In the M3 model of Table 3, the t value of the interaction item between philanthropic donations and the degree of disclosure of philanthropic information is -3.339 , which indicates that the degree of disclosure of philanthropic information will weaken the impact of philanthropic donations on innovation performance. That is, the higher the degree of disclosure of philanthropic donations, the weaker the impact of innovation performance. Suppose H3 gets support.

\subsection{Robustness Test}

In order to test the robustness of the above research results, this paper adopts the way of substituting variables and transforms the index measuring innovation performance into the number of patent grants. And then regress it again. The results are shown in Table 4.

In the M1 model in Table 4, philanthropic donations have a significant positive correlation with innovation performance. In the M3 model, the t value of the interaction between philanthropic giving and enterprise size is 4.415 , indicating that the size of the enterprise still plays a positive role in regulating the impact of philanthropic giving on innovation performance, which is consistent with the previous research. In the M3 model, the $t$ value of the interaction between philanthropic donations and the level of information disclosure is -4.357 , indicating that the level of philanthropic disclosure still weakens the impact of philanthropic donations on innovation performance, consistent with the previous article. Except that the impact of philanthropic donations on innovation performance is less significant than before in the M3 model, the other results are consistent with the previous ones, indicating that the conclusions of previous studies are robust and trustworthy. 
Table 5. Robustness analysis results

\begin{tabular}{|c|c|c|c|}
\hline Explanatory Variables & Innov (M1) & Innov (M2) & $\operatorname{Innov}(\mathrm{M} 3)$ \\
\hline \multirow{2}{*}{ (Constant) } & 16.109 & -505.665 & -468.072 \\
\hline & $(2.094)^{* * *}$ & $(-10.076)^{* * *}$ & $(-7.752)^{* * *}$ \\
\hline \multirow{2}{*}{ Phil } & 0.002 & 0.001 & 0.001 \\
\hline & $(3.450) * *$ & $(2.908) * * *$ & $(1.859) *$ \\
\hline \multirow{2}{*}{ Size } & & 23.271 & 13.887 \\
\hline & & $(11.551) * * *$ & $(4.314) * * *$ \\
\hline \multirow{2}{*}{ Disclo } & & -1.168 & 19.832 \\
\hline & & $(-0.533)$ & $(3.619) * * *$ \\
\hline \multirow{2}{*}{ Phil * Size } & & & 1.578 \\
\hline & & & $(4.415)^{* * *}$ \\
\hline \multirow{2}{*}{ Phil * Disclo } & & & -4.357 \\
\hline & & & $(-4.284) * * *$ \\
\hline \multirow{2}{*}{ Profit } & -23.788 & 53.278 & 50.561 \\
\hline & $(-0.446)$ & $(1.063)$ & $(0.965)$ \\
\hline \multirow{2}{*}{ Gro } & -0.643 & -0.892 & -0.590 \\
\hline & $(-0.331)$ & $(-0.495)$ & $(-0.331)$ \\
\hline $\operatorname{Indu}$ & Controlled & Controlled & Controlled \\
\hline Year & Controlled & Controlled & Controlled \\
\hline$N$ & 808 & 808 & 808 \\
\hline Adjusted $R^{2}$ & 0.068 & 0.201 & 0.219 \\
\hline
\end{tabular}

\section{Research Findings and Discussion}

\subsection{Enterprise Size: The Foundation of Corporate Philanthropy, the Driving Force of Innovation Performance}

This empirical test supports the assumption that enterprise size has a positive moderating role in the impact of philanthropic donations on innovation performance, which suggests that large-scale enterprises have an advantage in terms of acquiring outside resources through philanthropic giving for the sake of promoting innovation performance of enterprises. On the one hand, according to the bankruptcy concept of capital structure, SMEs themselves do not have sufficient financial and material resources, so SMEs are more likely to go bankrupt than large-scale ones. On the other hand, Wu Peng et al. (2012) find that the larger the size of the enterprise, the higher the value of the assets it holds, and the easier it is for banks and other financial institutions to trust. As a result, the external financing capability of the enterprise is stronger. Therefore, it can be seen that a large-scale enterprise has a strong ability to obtain external funds and the risk of philanthropic donations resulting in occupation of funds for the normal operation of an enterprise is small. Therefore, the size of the enterprise is the foundation of corporate philanthropic donations, and has a significant role in promoting cooperate philanthropy.

Philanthropic donations are an important way for enterprises to fulfill their social responsibilities and attain external resources. According to the theory of resource dependence, enterprises need to rely on external resources to maintain their normal survival and development. Xu Tao and Wang Ling (2012) and Frederick et al (2014) both find that enterprises can establish a good network mechanism for information exchange by establishing good relationship with external resource holders such as universities and research institutes through philanthropic donations, which can expand the scope of knowledge of enterprises and improve the innovation performance of enterprises has a positive role in promoting. In short, the scale of enterprises has a significant role in promoting philanthropic donations, thereby promoting the improvement of enterprise innovation performance. 


\subsection{Philanthropic Donations Information Disclosure: The Development of Innovative Performance Resistance}

Innovation is an important driving force for the development of an enterprise. The direction of innovation and development of an enterprise is an important part of the enterprise's trade secrets. A good innovation program can bring unlimited business opportunities, but most of the disclosure of philanthropic donations will allow companies to expose the risks of innovation programs, which affecting the company's innovation performance. As mentioned above, corporate philanthropy is a way for an enterprise to fulfill its social responsibilities. At the same time, it is also a way for a company to implement its business strategy and establish friendly relations with the outside world. The philanthropic donations made by a company maybe imply innovative direction of development. If the higher the degree of disclosure of philanthropic information, the direction of innovation and development of enterprises is more likely to be known by competitors, thereby affecting the innovation of enterprises. Frederick et al. (2014) find that enterprises tend to engage in philanthropic donations by direct donation because the state does not mandate the disclosure of direct donation while the donations through foundation enforce the disclosure of information. In summary, the level of disclosure of philanthropic information diminishes the impetus of philanthropic giving to innovation performance.

\subsection{Theoretical Significance and Practical Inspiration}

\section{(1) Theoretical significance}

First of all, this article enriches the research on charity donation and its influence. Previous studies mainly focused on the impact of philanthropic donations on corporate financial performance. Based on the theory of resource dependence, this paper studies the impact of philanthropic donations on innovation performance. It is not enough for the enterprises to rely solely on the resources within the enterprise if they want to meet the need for their survival and development, they also need to rely on external resources. Corporate philanthropy is conductive to creating a good corporate image and building good relationships with external resource holders. In particular, the direct donation of enterprises to universities and research institutes is beneficial to establishing good network research mechanisms for charity, strengthening communication of information, broadening the knowledge base of enterprises, and improving the innovation performance of them. At the same time, the paper also verifies that the scale of enterprises can promote the philanthropic donation and innovation performance. The bigger the scale is, the more favorable the access to external resources. When donating, the lager enterprises' sizes are, the better resources enterprises can obtain. Philanthropic donation provides a solid foundation to promote the improvement of enterprise innovation performance, which can provide reference for the future research on philanthropic giving and innovation performance.

Second, it verifies that the weakening effect of the degree of charity disclosure, which plays an role in the relationship between philanthropic donations and innovation performance, and this effectively explains why enterprises do not want to disclose philanthropic donation information. Corporate disclosure charity information will face the exposure of information on the direction of the development of the enterprise. It will be perceived to the further development direction of the enterprise by competitors and not conducive to the implementation of innovative strategies by enterprises. Especially in the highly competitive industries, enterprises establish a good relationship between universities, research institutions and other through charity donations, thereby promoting business innovation, but also face the pressure of disclosure of information. This paper enriched the research of charity donation and innovation performance from the perspective of information disclosure.

\section{(2) Practical Inspiration}

The present study finds that there are some important implications for the management practices of Chinese enterprises in order to answer the question of how enterprises can benefit from the charity donation, which includes the following two points: First, the enterprises should dialectically view the impact of philanthropic donations on innovation performance, Especially for small and medium-sized enterprises, they seek to carry out corporate philanthropic donations without damaging the normal operation of the enterprises, and promote enterprise innovation. Research shows that the scale of enterprises will affect the philanthropic donations of enterprises. The larger the scale of enterprises, the more opportunities for philanthropic donations will be. However, small-scale enterprises should make their own efforts according to their actual needs and must not "Puff Oneself Up to One's Own Cost "Otherwise, it is not conducive to the improvement of business innovation performance. Second, the study also finds that the disclosure of philanthropic information will weaken the role of philanthropic donations on the innovation performance of enterprises, because some philanthropic donations contain the direction of further development of enterprises, therefore, enterprises in the philanthropic donations should pay attention to the government's mandatory level of philanthropic information disclosure. Enterprises develop philanthropic donation strategy according to government policies and choose the appropriate way for 
further development strategies and innovative business direction of philanthropic donations, such as: direct donation.

\subsection{Research Deficiencies and Prospects}

Although this article has made some meaningful discoveries, there are still some shortcomings. First, because some companies lack in the amount of philanthropic donations and important data such as patent applications and authorizations, this article adopts the method of direct elimination, which may have some impact on the conclusion. If the company can provide these data in the future, the research result will be more reliable and authentic. Second, due to the restriction of mathematical statistics model, this study only studies the impact of philanthropic donations on innovation performance from the perspectives of enterprise size and information disclosure, and this is only a corner of this research field. Philanthropic donations will benefit the growth of enterprise value only when they are recognized by the market(Li Jingqiang \& Liu Fengjun,2010). Therefore, future research can be based on stakeholder perspectives and combine the knowledge of psychology in order to make a more comprehensive contribution on the positive impact on enterprise innovation resulted from philanthropic donations.

\section{References}

Acharya, V. V., \& Subramanian, K. V. (2009). Bankruptcy codes and innovation. Review of Financial Studies, 22(12), 4949-4988.

Balotti, M. F. (1998). Transcript of proceedings - corporate charity: societal boon or shareholder bust?

Chen, J., Dong, W., Tong, J. (2016). Corporate Philanthropy and Tunneling: Evidence from China. Journal of Business Ethics, 1-23.

Chen, K., Zhou, Y. G., \& Yang, G. L. (2) Enterprise scale,Government funding intensity and Innovation Performance. Scientific Management Research, (2), 9-12.

Chen, Q. Y., Ma, L. J., \& Yi, Z. H. (2017). Analyst coverage and corporate's innovation performance:the logic of china. Nankai Business Review, 20(3), 15-27.

Chen, S., Shi, X. B., \& Wu, S. Y. (2015). Impact of complementary assets and innovation asset synergy on performance — - from the prospect of moderating effect of environmental dynamism. Systems Engineering, (1), 61-67.

Dai, Y., Pan, Y., \& Feng, S. (2014). Are Chinese enterprises' Charitable Donations "Political Contribution?"Evidence from the Replacement of the Municipal Party Secretaries. Economic Research Journal, (2), 74-86.

Du Y., \& Chen, J. Y. (2016). Political Connections, Charitable Donations and Government Subsidies: Empirical Evidence from Money-losing Listed Companies in China. Journal of Economics and Finance, 42(5), 4-14.

Friedman, M. (1970). The social responsibility of business is to increase its profits. New York Times Magazine, (6), 173-178.

Gao Y. Q., Chen, Y. J., \& Zhang, Y. J. (2012). "Red Scarf" or "Green Scarf": A Study on Motivations of Philanthropic Donations by Private Enterprises. Management World, (8), 106-114.

Gao, Y. Q. (2010). Review on the Study of System Info of Corporate Social Responsibility in West. Contemporary Economy \& Management, 32(7), 13-19.

Gu, L. L., \& Ouyang, W. J. (2017). C Corporate Philanthropy, Marketing Capability and Firm Performance. Nankai Business Review, 20(2), 94-107.

Hu, J., Wang, H. J., \& Song, X. Z. (2017). Does Philanthropic Donations have Strategic Effect? Evidence from Competition in Product Market. Journal of Audit and Economics, 32(4), 83-92.

Huang, J. J. (2017). Research on the university-industry collaborative innovation efficiency and its affecting factors. Soft Science, 31(5), 38-42.

Jiang, R. C., Ma, L. K., \& Zheng, L. (2016). Inverted u-shaped relationship research between charitable donations and enterprise performance:an empirical analysis based on the view of endogenous. Modern Finance and Economics-Journal of Tianjin University of Finance and Economics, (1), 92-103.

Li, J. Q., \& Liu, F. J. (2010). Empirical study on the market impact of corporate philanthropic giving — taking the donation in "5·12" earthquake for example. China Soft Science, (6), 160-166.

Li, S., Hong, T., \& Wu, C. P. (2012). Patent output, intellectual property protection and market value: evidence from china's listed companies. Nankai Business Review, 15(6), 4-13. 
Li, Y. P., Jia, H., \& Meng, X. F. (2009). Study on Disclosure of Social Responsibility in Corporate Web Site. Soft Science, 23(6), 102-105.

Liu, W., Fan, X., \& Wu, J. (2013). Study on the factors that affect the proneness of university-industry cooperation for enterprises. Chinese Journal of Management, 10(5), 740.

Liu, Y. (2015). A Comparative Study of the Impact of Business Sponsorship and Philanthropy on Corporate Identity and Product Evaluation. Consume Economics, (2), 59-68.

Lu, Z. W., \& \& Liu, C. L. (2017). Research on the Impact of Charitable Donations on Firm Performance Based on Motivation Awareness - The Regulatory Effects of Basic Corporate Social Responsibility. Modern Economic Research, (9), 33-40.

Ni, Y. Z., He, C., N. Y. Z., \& Chen, H. (2016). Executives' Exceeded Compensation, Regional Disparities of Institutional Environment and Charitable Donation. Journal of Hubei University of Economics, 14(2), 69-74.

Park, J., Choi, J., \& Yeu, M. (2016). Relationship between corporate philanthropy and consumer loyalty - the mediating role of gratitude, trust and commitment: South Korean consumer perspectives. Academy of Marketing Studies Journal, 20.

Peng, W. U., Wei, S., \& Chen, T. P. (2012). Factors in sme financing:a case study of jiangsu. Journal of Southeast University, 14(6), 25-29 .

Sun, H. C., Zhao, G. J., \& Wang, P. P. (2006). Resource Abstraction and Business Innovation. Iner Mongolia Social Sciences (Chinese), 27(3), 69-71.

Wang B., \& Zhang M. (2015). Marketization, collaboration with academics and innovation performance of enterprises. Studies in Science of Science, 33(5), 748-757.

Wang, H., \& Qian, C. (2011). Corporate philanthropy and corporate financial performance: the roles of stakeholder response and political access. Academy of Management Journal, 54(6), 1159-1181.

Wang, X. Y., Jiao, H. B., \& Li, W. (2013). Contradiction problems analysis and solving of enterprise innovation resources management based on innovation process. Soft Science, 27(10), 29-32.

Wang, Y., \& Cao, T. Q. (2017). On Peer Effects of Corporate Philanthropy: A Study Based on Board Networks. Journal of Economics and Finance, 43(8), 69-81.

Wu C. (2015). The Empirical Study On Relationship Between Technology Innovation And Competiveness Of Guangdong Enterprise.

Xu, T., \& Wang, L. (2012). Win-win corporate education donation. Science News, (9).

Yang, S. Y. (2013). Legal and Economic Analysis of the Disclosure System of Corporate Philanthropy and Donations. Exploration, (5), 191-193.

Zhang, A. Y. (2011). On information disclosure of corporate charitable donation—research of necessity and feasibility of system building. Technoeconomics \& Management Research, (4), 60-63.

Zhang Y., \& Peng J. (2016). The Effect of Network Relationship Feature of Science and Technology Small and Micro Enterprises Alliance on Enterprise Innovation Performance-Based on the Intermediary Role of Innovation Resources. Science and Technology Management Research, 17, 140-147.

Zhu, J. F., \& Zhao, H. J. (2010). Charitable donations will enhance the financial performance of business? - A Shanghai Stock Exchange from the empirical test of a listed company. Friends of Accounting, (4), 84-87.

\section{Copyrights}

Copyright for this article is retained by the author(s), with first publication rights granted to the journal.

This is an open-access article distributed under the terms and conditions of the Creative Commons Attribution license (http://creativecommons.org/licenses/by/4.0/). 